\title{
THE MECHANICS OF BREATHING IN DIFFERENT BODY POSITIONS. I. IN NORMAL SUBJECTS
}

\author{
By ERNST O. ATTINGER, ${ }^{1}$ R. GRIER MONROE, AND MAURICE S. SEGAL
}

(From the Lung Station (Tufts) and Department of Inhalation Therapy, Boston City Hospital, and the Department of Medicine, Tufts University School of Medicine, Boston, Mass.)

(Submitted for publication July 8, 1955 ; accepted April 16, 1956)

In preliminary experiments some striking differences in the mechanics of breathing in different body positions were observed. In view of those findings it was thought worthwhile to carry out a more extensive study with the anticipation that the results might shed some light on the factors which influence the compliance and mechanical resistance of the lung.

Compliance is defined as the volume change brought about by one centimeter of water pressure ( $\mathrm{L}$. per $\mathrm{cm} . \mathrm{H}_{2} \mathrm{O}$ ). The lower the compliance the stiffer the lung and vice versa. Mechanical resistance measures the amount of pressure necessary to obtain a certain flow rate and is expressed as $\mathrm{cm} . \mathrm{H}_{2} \mathrm{O}$ per L. per sec.

In this paper, mechanical resistance includes both the resistance to air flow per se and the resistance to tissue deformation. The latter resistance has been measured to be about 30 to 40 per cent of the total mechanical resistance in normal lungs (1). Because the pressure flow relationships are not linear, the mechanical resistance changes continuously over the respiratory cycle especially in patients with increased resistance. In order to get better comparative values over an entire respiratory cycle, values for mean mechanical resistance are given in this paper.

\section{METHODS}

Intraesophageal pressures were substituted for intrapleural pressures. The method used was essentially the one described by Mead and Whittenberger $(2,3)$, employing an esophageal balloon, $15 \mathrm{~cm}$. in length and inflated with $1 \mathrm{ml}$. of air. All pressures were measured by mechano-electrical transducers. Flow rates were measured by a pneumotachograph. The volume flow rate was electrically integrated by a condenser-resistor unit. Because the integrator only maintained linearity for $10 \mathrm{sec}-$ onds, an automatic switch was provided which discharged the condensers at determined time intervals ( 5 to $8 \mathrm{sec}-$ onds). A controlled secondary circuit made it possible

\footnotetext{
${ }^{1}$ Research Fellow in Medicine, Tufts University School of Medicine, Boston, Mass.
}

to correct for volume differences caused by the respiratory quotient and temperature and humidity changes between the inspired and expired air. Consequently the base line remained horizontal in a given midposition. The volumes measured are the inspired volumes at $25^{\circ} \mathrm{C}$ (not saturated) and are reported as such. This would reduce the compliance values about 7 per cent as compared to values corrected for B.T.P.S. All electrical outputs were fed into a Sanborn four channel recording unit.

Since considerable variations may occur between individual respiratory cycles caused by heart beats, at least two series of ten cycles each were measured in each position and at each respiratory rate. The mean compliance of the two series was required to check within 0.03 for values above 0.15 , within 0.02 for values above 0.1 and within 0.01 for values below 0.1. Resistive pressures were measured by drawing the corrected static intrapleural pressure and obtaining the difference between dynamic and static intrapleural pressure at each $1 / 10$ of a second for slow respiratory rates and at each $1 / 25$ of a second for rapid rates. The resistive pressure was divided by the flow rate existing at that particular moment and plotted on graph paper-first as pressure against flow and second, as mechanical resistance against time. The mean was measured planimetrically. All pressures were calibrated by a water manometer and flow rates and volumes with suitable Fischer and Porter flowmeters before and after the experiment.

In two subjects with spontaneous pneumothorax intrapleural pressures were measured through an 18-gauge needle and in two patients with pleural effusion with an indwelling 14-gauge polyethylene catheter and a Statham strain gauge whose zero point was the posterior axillary line.

The studies were done on eight subjects who by history, clinical, and $x$-ray findings were free of chronic pul-

TABLE I

Physical characteristics of eight normal subjects

\begin{tabular}{|c|c|c|c|c|c|}
\hline Patient & Sex & Age & $\underset{\left(m^{2}\right)}{\text { B.S. }}$ & $\underset{\substack{\text { (erect) } \\
(m l .)}}{\text { e.c. }}$ & $\underset{(L . / m i n .)}{\text { M.B.C. }}$ \\
\hline $\begin{array}{l}\text { B. D. } \\
\text { W. C. } \\
\text { J. R. } \\
\text { M. G. } \\
\text { J. T. } \\
\text { C. B. } \\
\text { J. C. } \\
\text { H. T. }\end{array}$ & $\begin{array}{l}\mathbf{M} \\
\mathbf{M} \\
\mathbf{F} \\
\mathbf{M} \\
\mathbf{M} \\
\mathbf{M} \\
\mathbf{M} \\
\mathbf{M}\end{array}$ & $\begin{array}{l}35 \\
37 \\
21 \\
30 \\
23 \\
37 \\
49 \\
20\end{array}$ & $\begin{array}{l}1.84 \\
1.70 \\
1.56 \\
1.80 \\
1.86 \\
1.78 \\
1.65 \\
1.65\end{array}$ & $\begin{array}{l}4,300 \\
3,500 \\
2,900 \\
4,500 \\
4,000 \\
3,600 \\
3,835 \\
2,200\end{array}$ & $\begin{array}{r}115 \\
96 \\
140 \\
\\
128 \\
80\end{array}$ \\
\hline
\end{tabular}


monary disease. Their physical characteristics are given in Table I. One of the subjects (M. G.) was studied twice. Two of those subjects (J. C. and H. T.) had a spontaneous pneumothorax, and intrapleural and intra- esophageal pressures were measured simultaneously. In addition, intrapleural and intraesophageal pressures were compared in two patients with pleural effusion. The positions studied by intraesophageal pressure were the
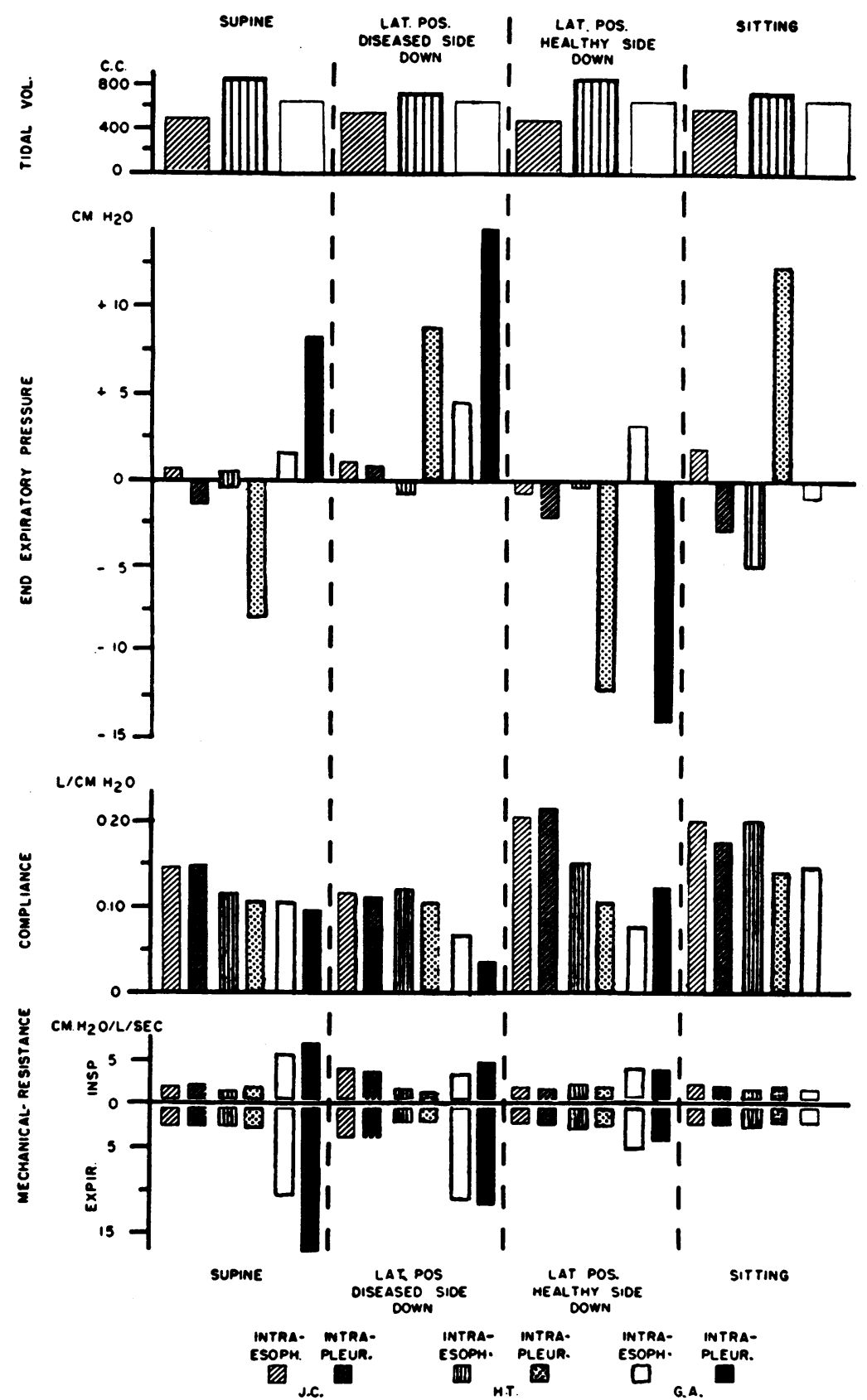

THE MECHANICS OF BREATHING IN DIFFERENT BODY POSITIONS. COMPARISON BETWEEN INTRA-ESOPHAGEAL AND INTRA-PLEURAL MEASUREMENTS IN TWO PATIENTS WITH SPONTANEOUS PNEUMOTHORAX (J.C.AND H.T.) AND ONE PATIENT WITH PLEURAL EFFUSION(G.A)

Figure 1 
supine in nine experiments, the sitting in nine experiments and the prone in six experiments. Most positions were studied during slow and fast respiratory rates.

\section{RESULTS ${ }^{2}$}

\section{Comparison between intrapleural and intra- esophageal pressures}

Intrapleural and intraesophageal pressures were measured simultaneously in two subjects with

2 The statistical technique used in the analysis of these results makes no assumption as to the form of the distribution of the variables studied in the general population. Such statistical methods are called nonparametric or distribution-free methods. Since they are valid for any parent population, they could be applied to samples of normal population. On the other hand, using a normal theory test with a given level of significance does not assure that the probability of certain type errors will not occur if the normality of the distribution is not known.

If comparisons were made between any two groups, rates, positions or their combinations, the findings were treated according to the signed Rank test for paired ob- spontaneous pneumothorax (10 per cent collapse) and in two patients with pleural effusion. The results in three of these patients during slow breathing are shown in Figure 1. In all cases, the intrapleural pressure differences were somewhat greater than the intraesophageal pressure differences. During rapid breathing, intraesophageal pressure differences were sometimes considerably less than intrapleural pressure differences though the pattern looked very similar in both tracings (Figures 2A and 2B). End expiratory intrapleural pressure was, in general, more negative than end servations where there were matched pairs or the Sign test and Sum of Ranks test, where there were unequal groups. When several groups, positions or rates were compared together, the method used was an analysis of variance by Ranks.

Only those results which occurred at the 5 per cent level of confidence or beyond were reported as significant. That means that the possibility of whatever comparison was made would occur five times or less out of one hundred, which places it well beyond the range of chance occurrence.
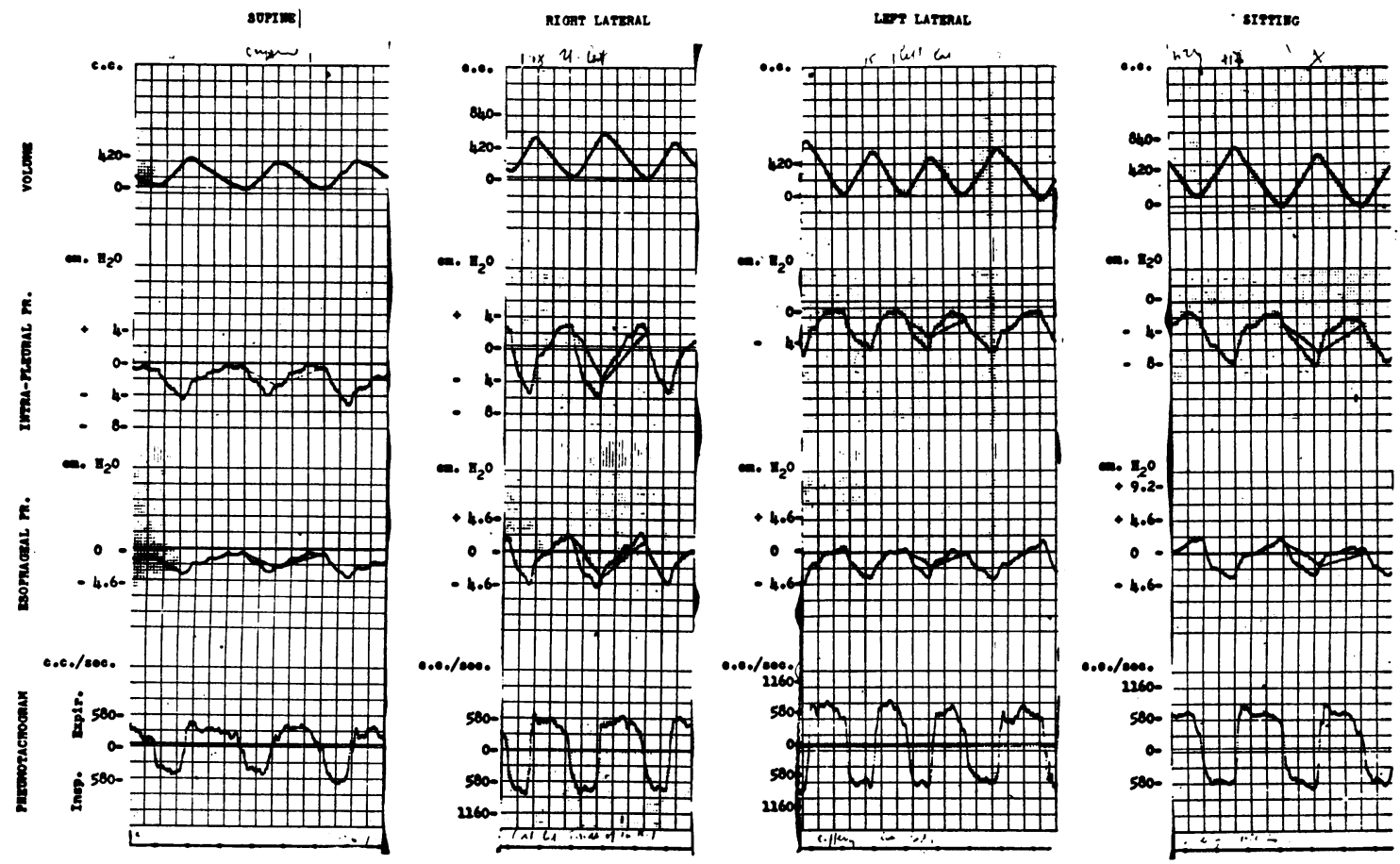

Fig. 2a. J. C., 49 Yrs., Male; Normal with Spontaneous Pneumothorax on Right Side with 10 Per Cent Collapse

Comparison of intrapleural and intraesophageal pressures in a normal patient with spontaneous pneumothorax on the right side with 10 per cent collapse. During quiet breathing, the pressure difference in the intrapleural and esophageal tracings are nearly the same although the absolute pressure levels are slightly higher in the intrapleural tracings depending upon position. 

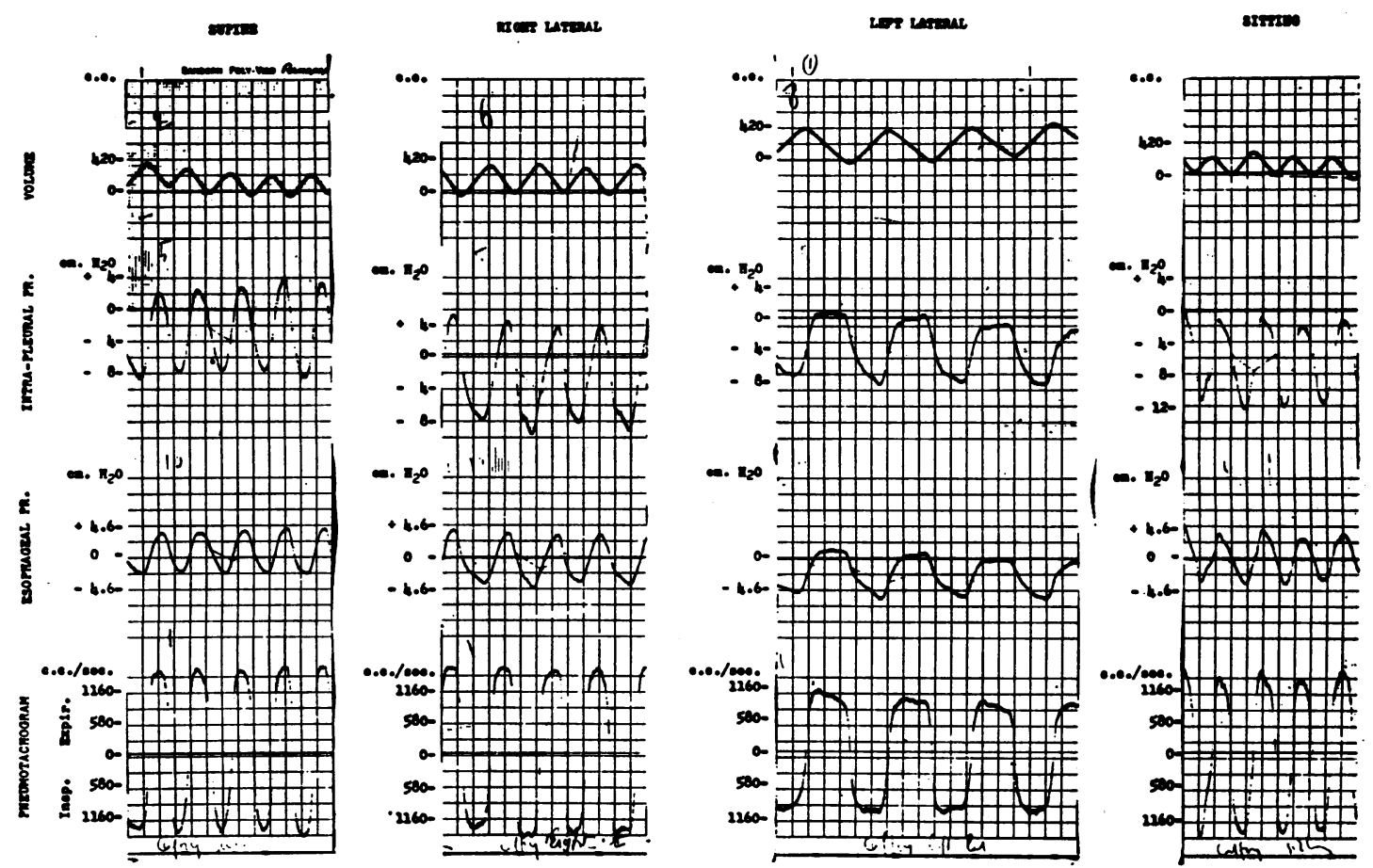

Fig. 2B. J. C., 49 Yrs., Male; Normal with Spontaneous Pneumothorax on Right Side with 10 Per Cent Collapse

Comparison of intrapleural and intraesophageal pressures in a normal patient with spontaneous pneumothorax on the right side with 10 per cent collapse during rapid breathing.

Note the marked dampening in the esophageal pressure.

expiratory intraesophageal pressure. A notable exception was the study in the lateral position with the patients lying on the diseased lung. Patient G. A. shows a higher intrapleural pressure in the supine position as the result of the hydrostatic pressure of the fluid. No reliable intrapleural pressures could be obtained in the sitting position on this patient. Subject H. T. showed a considerably higher intrapleural pressure in the sitting position. He had a small bronchopleural fistula at the time of the study and his intrapleural pres- sure tracing showed light damping in the sitting position.

The compliance values compare well for subject J. C. in all positions. Subject H. T. has a reduction in intrapleural as compared to intraesophageal compliance lying on the healthy side and in the sitting position. Patient G. A. shows a lower intrapleural compliance lying on the diseased side and a higher intrapleural compliance lying on the healthy side.

The values for intrapleural and intraesophageal

TABLE II

Mechanics of breathing in patient $A . A ., 65$ years, male, with pleural effusion on the right side (Study in supine position before and after removal of 1,000 ml. of fluid)

\begin{tabular}{|c|c|c|c|c|c|c|c|c|c|}
\hline \multirow{2}{*}{$\begin{array}{l}\text { Respira- } \\
\text { tory } \\
\text { rate }\end{array}$} & \multirow[b]{2}{*}{$\begin{array}{c}\text { Tidal } \\
\text { volume }\end{array}$} & \multicolumn{2}{|c|}{ End expir. pressure } & \multicolumn{2}{|c|}{ Compliance } & \multicolumn{2}{|c|}{$\begin{array}{l}\text { Mean mech. resist. } \\
\text { during insp. }\end{array}$} & \multicolumn{2}{|c|}{$\begin{array}{l}\text { Mean mech. resist. } \\
\text { during expir. }\end{array}$} \\
\hline & & $\begin{array}{l}\text { Intra } \\
\text { pl. pr. }\end{array}$ & $\begin{array}{c}\text { Esoph. } \\
\text { pr. }\end{array}$ & $\begin{array}{l}\text { Intra } \\
\text { pl. pr. }\end{array}$ & $\begin{array}{l}\text { Esoph. } \\
\text { pr. }\end{array}$ & $\begin{array}{l}\text { Intra } \\
\text { pl. pr. }\end{array}$ & $\begin{array}{l}\text { Esoph. } \\
\text { pr. }\end{array}$ & $\begin{array}{l}\text { Intra } \\
\text { pl. pr. }\end{array}$ & $\begin{array}{l}\text { Esoph. } \\
\text { pr. }\end{array}$ \\
\hline $\begin{array}{c}\text { Before } \\
24 \\
60\end{array}$ & $\begin{array}{l}560 \\
500\end{array}$ & $\begin{array}{l}+12.0 \\
+12.0\end{array}$ & $\begin{array}{l}+2.5 \\
+3.0\end{array}$ & $\begin{array}{l}0.08 \\
0.052\end{array}$ & $\begin{array}{l}0.087 \\
0.072\end{array}$ & $\begin{array}{l}5.40 \\
6.75\end{array}$ & $\begin{array}{l}4.75 \\
5.25\end{array}$ & $\begin{array}{l}9.25 \\
5.70\end{array}$ & $\begin{array}{l}8.80 \\
5.50\end{array}$ \\
\hline $\begin{array}{c}\text { After } \\
24 \\
88\end{array}$ & $\begin{array}{l}450 \\
280\end{array}$ & $\begin{array}{l}+1.0 \\
-2.5\end{array}$ & $\begin{array}{l}-2.0 \\
-5.2\end{array}$ & $\begin{array}{l}0.12 \\
0.043\end{array}$ & $\begin{array}{l}0.128 \\
0.097\end{array}$ & $\begin{array}{l}2.60 \\
3.50\end{array}$ & $\begin{array}{l}4.30 \\
3.30\end{array}$ & $\begin{array}{l}5.10 \\
2.70\end{array}$ & $\begin{array}{l}5.30 \\
3.15\end{array}$ \\
\hline
\end{tabular}


mechanical resistance compare fairly well in subjects J. C. and H. T. Patient G. A. shows a somewhat higher intrapleural resistance in the supine position and lying on the diseased side, while it is somewhat lower lying on the healthy side. The direction of positional changes is the same for intraesophageal and intrapleural compliance and mechanical resistance.
In order to get some ideas about the influence of a pleural effusion upon these differences, a patient with pleural effusion before and after a tap of $1000 \mathrm{ml}$. fluid was studied. The results are presented in Table II. Both intrapleural and intraesophageal pressures become more negative after the tap. Both compliances increase for slow respiratory rates. The drop in intrapleural compli-

TABLE III

Mechanics of breathing: Results in eight normal subjects in supine, sitting and prone positions during slow and fast respiratory rates

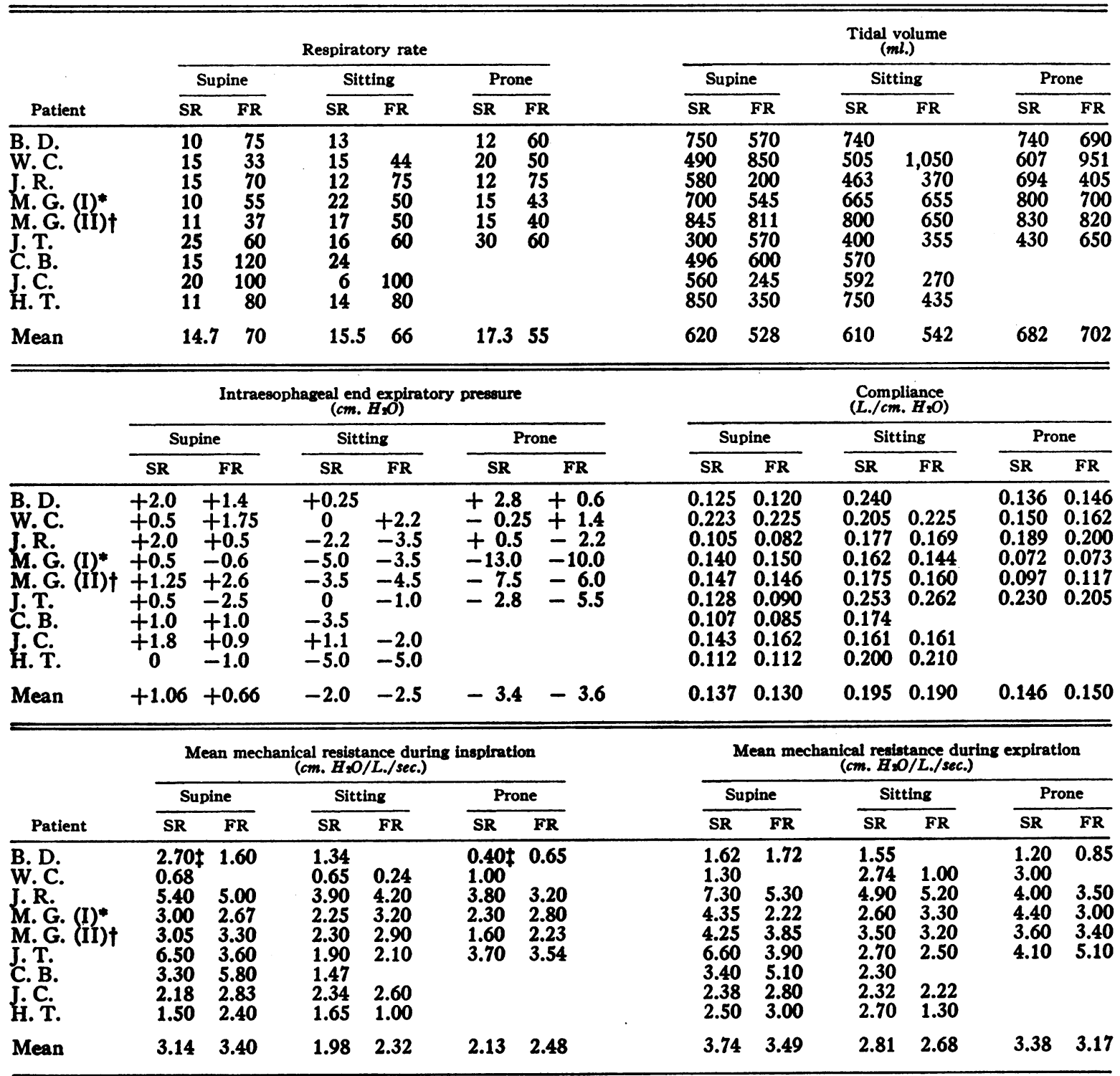

* First study.

+ Second study-two months later.

$\mp$ Marked interference of heart beats. 
ance with increase in rate is particularly noticeable after the pleural tap, while the drop in intraesophageal compliance though present is less significant. Intraesophageal mechanical resistance is somewhat lower before the tap, both for inspiration and expiration, and slightly higher after the tap for slow respiratory rates. Corresponding to the marked drop noted in intrapleural compliance during fast breathing, the drop in intrapleural resistance is less under these conditions.

From these results, it would seem that intraesophageal pressures give an adequate picture of the effects of positional changes on the mechanics in breathing. However, in patients with unilateral dysfunction (pleural effusion, penumothorax with bronchopleural fistula) the effects of positional changes on the intrapleural pressures of the affected lung are considerably more marked than on the intraesophageal pressures.

The difference between intraesophageal and intrapleural pressure depends upon the characteristics of the measuring device, its location within the esophagus and the characteristics of the esophageal wall and the adjacent structures (2-5). Difficulties may ensue in employing intraesophageal pressures as a guide for the determination of absolute lung distention. Therefore, an evaluation of the work of breathing using intraesophageal pressure measurements will not take into account the metabolic work necessary to maintain the inflation of the lung at a given midposition.

\section{Positional changes}

The results for the three positions at two different respiratory rates are presented in Table III.

End expiratory pressures are consistently more negative in the sitting than in the supine position. In four out of six normals, they were more negative in the prone than in the sitting position. These differences are significant at the 2 per cent level. There are no significant differences in endexpiratory pressures between slow and fast respiratory rates in any position. In general, subjects who show a decrease in tidal volume with an increase in respiratory rate, demonstrate an increase in negativity.

Compliance values are considerably higher in the sitting than in the supine position. The values in the prone position are usually intermediate with considerable scattering of the individual scores.
These differences are significant at the 2.5 per cent level. There are no differences for compliance values at different rates in any of the positions studied.

Mechanical resistance is somewhat higher during expiration than during inspiration. The difference is significant for all positions for slow respiratory rates and also for the prone position for fast respiratory rates. Neither inspiratory nor expiratory resistance change significantly at various respiratory rates in any position. Mechanical resistance is generally lower in the sitting and prone positions as compared to the supine position. The subjects with a high resistance in the supine position show the greatest changes with variation of body position. However, the scatter of the individual results is such that the difference of the means is not statistically significant.

\section{DISCUSSION}

In changing from the erect to the recumbent position there is, in general, only a slight decrease in total lung capacity, vital capacity, and residual volume but a large decrease in expiratory reserve volume with an inadequate compensatory increase in the inspiratory reserve volume $(6-10)$. Pulmonary mixing is poorer in the supine than in the erect position (11-18). In the lateral position the lower lung shows a decreased expiratory reserve volume. However, the oxygen consumption, minute ventilation, vital capacity, and inspiratory reserve volume are increased (19). During thoracic surgery, there is considerably more carbon dioxide retention in the lateral position than in the supine or prone position (20).

The pressure-volume curves of the relaxed thorax (relaxation curves) are parallel in the sitting, supine and Trendelenburg positions $(21,22)$. The relaxation volume of the thorax is nearer the expiratory volume in the recumbent and Trendelenburg positions. Under these conditions the lung assumes a lower midposition. In the erect position, the weight of the thorax tends to increase the intrathoracic pressure whereas the pull of the abdominal contents tends to decrease it. Judging from the relaxation curves, the pull of the abdominal contents seems to predominate.

Although respiratory rates and tidal volumes in the different body positions were within the same 
range in the experiments (only the prone position showed a considerable increase in the minute ventilation), changes in body position resulted in considerable changes of end expiratory pressure, compliance, and mechanical resistance. The changes in end expiratory pressures are greater than one would expect from changes in midposition alone $(23,24)$. If the observed changes in compliance were only the result of changes in midposition, they should also have been noted in changing from slow to rapid respiratory rates, where marked changes in tidal volumes and midposition occurred. Therefore, one has to look for additional factors which could contribute to the observed changes in the mechanics of breathing.

A decrease in hydrostatic pressure by removal of intrapleural fluid leads to an increase in compliance and a decrease in mechanical resistance. Changes in hydrostatic pressure could influence the physical properties of the lung directly, but they also can affect both the distribution of pulmonary blood flow and the forces acting upon the chest wall, mediastinum and diaphragm. The latter in turn changes the shape of the thorax and, therefore, the midposition of the lung.

The amount and distribution of blood within the lungs influences pulmonary surface tension and, therefore, compliance and mechanical resistance. In patients with mitral stenosis (25) studied in the sitting position, the deviation from normal values was more marked when the patients were in failure. Some of the changes observed in the supine position may be the result of increased thoracic blood volume, thus simulating to some extent the changes observed in mitral stenosis. Oser, Ruston, and Ryan (26) showed that the increase in venous hydrostatic pressure in the erect position can exceed the venous tone below the diaphragm and result in blood trapping and reduction of right atrial pressure.

Another factor to be considered is the amount of unequal ventilation and the opening up of additional ventilatory space when the lung volume is increased (27). Our results seem to indicate that this is a minor factor in normal lungs, compliance being constant at different respiratory rates (28).

The reported changes in the mechanics of breathing are probably of no practical importance in normal subjects who have a large functional re- serve and are capable of compensating automatically for the occurring changes. However, the problem is quite different for patients with cardiopulmonary disease. Even for the normal subject, it is important to report results of pulmonary function tests with the body position in which the patient was studied. The changes with body position can exceed the variation of normal values in a given position.

\section{SUMMARY}

1. The mechanics of breathing were studied in eight normal subjects.

2. Intrapleural and intraesophageal pressures were compared in four patients in different body positions. Intrapleural pressure differences were usually somewhat greater than intraesophageal pressures. End expiratory intraesophageal pressure is usually more positive than end expiratory intrapleural pressure. The difference varies from subject to subject and in each depending upon the body position. Intraesophageal pressures seem to be adequate for the measurement of the mechanics of breathing, but unsuitable for the determination of absolute lung distention (midposition).

3. Compliance and mechanical resistance were measured during slow and rapid breathing in the supine, sitting and prone positions.

4. Compliance was lowest in the supine and highest in the sitting position and did not change with change in respiratory rate.

5. Mechanical resistance was usually highest in the supine and lowest in the sitting position, expiratory resistance being somewhat higher than inspiratory resistance in all positions studied.

6. Some of the physiologic factors which might contribute to the observed changes are discussed.

7. The full significance of pulmonary function testing can only be determined after considering the body position during the tests.

\section{REFERENCES}

1. McIlroy, M. B., Mead, J., Selverstone, N. J., and Radford, E. P., Measurements of lung tissue viscous resistance using gases of equal kinematic viscosity. J. Applied Physiol., 1955, 7, 485.

2. Mead, J., and Whittenberger, J. L., Physical properties of human lungs measured during spontaneous respiration. J. Applied Physiol., 1953, 5, 779. 
3. Mead, J., McIlroy, M. B., Selverstone, N. J., and Kriete, B. C., Measurement of intraesophageal pressure. J. Applied Physiol., 1955, 7, 491.

4. Cherniack, R. M., Farhi, L. E., Armstrong, B. W., and Proctor, D. F., A comparison of esophageal and intrapleural pressure in man. J. Applied Physiol., 1955, 8, 203.

5. Attinger, E. O., and Segal, M. S., Comparison of intraesophageal and intrapleural pressures. In preparation.

6. Anthony, A. J., Untersuchungen über Lungenvolumina und Lungenventilation. Deutsche Arch. klin. Med., 1930, 167, 129.

7. Bohr, C., Die funktionellen Änderungen in der Mittellage und Vitalkapazität der Lungen. Normales und pathologisches Emphysem. Deutsche Arch. klin. Med., 1907, 88, 385.

8. Christie, C. D., and Beams, A. J., The estimation of normal vital capacity with especial reference to the effect of posture. Arch. Int. Med., 1922, 30, 34.

9. Hurtado, A., and Fray, W. W., Studies of total pulmonary capacity and its subdivisions. III. Changes with body posture. J. Clin. Invest., 1933, 12, 825.

10. Briscoe, J. C., The mechanism of post-operative massive collapse of the lungs. Quart. J. Med., 1920, 13, 293.

11. Blair, E., and Hickam, J. B., The effect of change in body position on lung volume and intrapulmonary gas mixing in normal subjects. J. Clin. Invest., 1955, 34, 383.

12. Bates, D. V., Fowler, W. S., Forster, R. E., and Van Lingen, B., Uniformity of alveolar ventilation at different lung volumes. J. Applied Physiol., 1954, 6, 598.

13. Martin, C. J., Cline, F., Jr., and Marshall, H., Lobar alveolar gas concentrations: Effect of body position. J. Clin. Invest., 1953, 32, 617.

14. Mundt, E., Schoedel, W., and Schwarz, H., ther die Gleichmässigkeit der Lungenbelüftung. Pflüger's Arch. f. d. ges. Physiol., 1940, 244, 99.

15. Rauwerda, P. E., Unequal ventilation of different parts of the lung and determination of cardiac output. Dissertation, Groningen University, 1948.

16. Roelsen, E., The composition of the alveolar air investigated by fractional sampling. Comparative investigations on normal persons and patients with bronchial asthma and pulmonary emphysema. Acta med. Scandinav., 1939, 98, 141.
17. Roelsen, E., Fractional analysis of alveolar air after inspiration of hydrogen as a method for the determination of the distribution of inspired air in the lungs. Examination of normal persons and of patients suffering from bronchial asthma and pulmonary emphysema. Acta med. Scandinav., 1938, 95, 452.

18. Rohrer, F., Der Strömungswiderstand in den menschlichen Atemwegen und der Einfluss der unregelmässigen Verzweigung des Bronchial systems auf den Atmungsverlauf in verschiedenen Lungenbezirken. Pflüger's Arch. f. d. ges. Physiol., 1915, $162,225$.

19. Vaccarezza, R. F., Lanari, A., Bence, A. E., and Labourt, F., Influencia del decubito lateral sobre el resposo pulmonar. Estudio funcional de cada pulmón por separado. Medicina, Buenos Aires, 1942, 2, 279.

20. Beecher, H. K., in Problems in Ventilation. A panel discussion. Anesthesiology, 1954, 15, 416.

21. Rohrer, F., Der Zusammenhang der Atemkräfte und ihre Abhängigkeit vom Dehnungszustand der Atmungsorgane. Pflüger's Arch. f. d. ges. Physiol., 1916, 165, 419.

22. Rahn, H., Otis, A. B., Chadwick, L. E., and Fenn, W. O., The pressure-volume diagram of the thorax and lung. Am. J. Physiol., 1946, 146, 161.

23. Stead, W. W., Fry, D. L., and Ebert, R. V., The elastic properties of the lung in normal men and in patients with chronic pulmonary emphysema. J. Lab. \& Clin. Med., 1952, 40, 674.

24. Butler, J., and Arnott, W. M., The work of pulmonary ventilation at different respiratory levels. Clin. Sc., 1955, 14, 703.

25. Mead, J., Frank, N. R., Lindgren, L., Gaensler, E. A., and Whittenberger, J. L., A technic for the measurement of pulmonary compliance and resistance: Its application to normal patients and patients with mitral stenosis. Clin. Res. Proc., 1953, 1, 116.

26. Oser, B. M., Ruston, J. R., and Ryan, J. M., The effect of tilting on the right atrial pressures of patients with heart failure. Clin. Res. Proc., 1955, $3,197$.

27. Bernstein, L., The discontinuity in the pressure volume curve of the rabbit's lung. J. Physiol., 1954, 124, $35 \mathrm{p}$.

28. Attinger, E. O., Herschfus, J. A., and Segal, M. S., The mechanics of breathing in different body positions. II. In cardiopulmonary disease. J. Clin. Invest., 1956, 35, 912. 